\section{TOTAL ENUCLEATION OF THE PROSTATE IN ADVANCED OLD AGE.}

By P. J. FREYER, M.A., M.D., M.CH. R.U.I., SLRGEON TO KING EDWARD VII.'S HOSPITAL FOR OFFICERS AND TO ST. PETER'S HOSPITAL, LONDON.

[THE first part of this paper, which was an introductory address delivered before the Reading Pathological Society, was taken up with a description of the various steps in Mr. Freyer's operation of total enucleation of the prostate and the anatomical and pathological considerations tha render the operation feasible. These have already been published in THE LANCET. Mr. Freyer continued by directing attention to the application of the operation in the case of octogenarians.]

One of the most remarkable features of this operation is the success that has attended its employment in patients of very advanced ages. Amongst 134 patients on whom I have performed the operation to date there were seven octogenarians and one bordering on this period of life, aged 79 years. Seven of them are alive at the present time, most of them in excellent health, and all able to retain and to pass urine normally. The remaining patient, in whom the prostate was carcinomatous, after complete recovery from the operation died suddenly from heart disease. From these facts it would appear that age has little influence on the results of the operation, provided that the vital organs (and particularly the kidneys) are unaffected or fairly sound. Nevertheless, patients of this age cause much anxiety, and the operation should not be undertaken in such cases unless the most careful and tender nursing is available as well as the constant personal supervision of the surgeon. The details of these eight cases are as follows, the original numbers of the cases in the whole series being retained.

CASE 15.-The patient, aged 79 years, was seen in consultation with Mr. J. H. Scott of Camberley on June 10th, 1902. There had been prostatic symptoms for three years. The patient was completely dependent on the catheter for nine months. The catheterism was painful and accompanied by hæmorrhage at times, also orchitis. The sound was passed but no stone was found. The prostate was much enlarged per rectum, particularly on the left. It was bilobed, rather hard, but moveable over the bowel. On June 23rd, Mr. C. Carter Braine being the anæsthetist, Mr. Scott and Mr. H. Frankling assisting, I made a cystoscopic examination of the patient and saw a valvular outgrowth from the left lobe, of the size of a gooseberry, projecting into the bladder. Suprapubic cystotomy was forthwith performed. The prostate being rendered prominent in the bladder and fixed by a finger of the right hand in the rectum, with the nail of the forefinger of the left hand in the bladder I scraped through the mucous membrane over the valvular prominence and detached it from the tumour all round. With the point of the finger I then rapidly enucleated the left lobe in its capsule from the sheath and urethra and delivered it into the bladder. The right lobe was similarly enucleated and both were withdrawn from the bladder by forceps. The urethra was left uninjured, covering the catheter. There was some oozing of blood which was controlled by hot boric irrigations. A drainage tube was inserted and the abdominal wound was sutured. Mr. Braine timed the operation, which from the moment I took the scalpel to perform suprapubic cystotomy till the wound was sutured occupied ten minutes. The patient bore the operation well but was so sick from the anæsthetic that for three days he had to be fed entirely by the rectum. On June 29 th the temperature rose to $103^{\circ} \mathrm{F}$. and the right parotid gland suddenly swelled to a large size, and on July 2nd there was swelling of the right testicle. Both glands subsided without suppuration. What the cause of the swelling of the parotid was-whether due to chill, the result of rectal feeding, or occurring as it occasionally does after operations on the pelvic viscera and abdomen-I am unable to say. I feared at first that it might be due to septicremia, but this was obviously not the case. Urine began to pass naturally on July 16 th and the abdominal wound was completely closed on the 27th. I saw this patient. recently, more than two years after the operation. He was. in excellent health, had put on much flesh, and assured

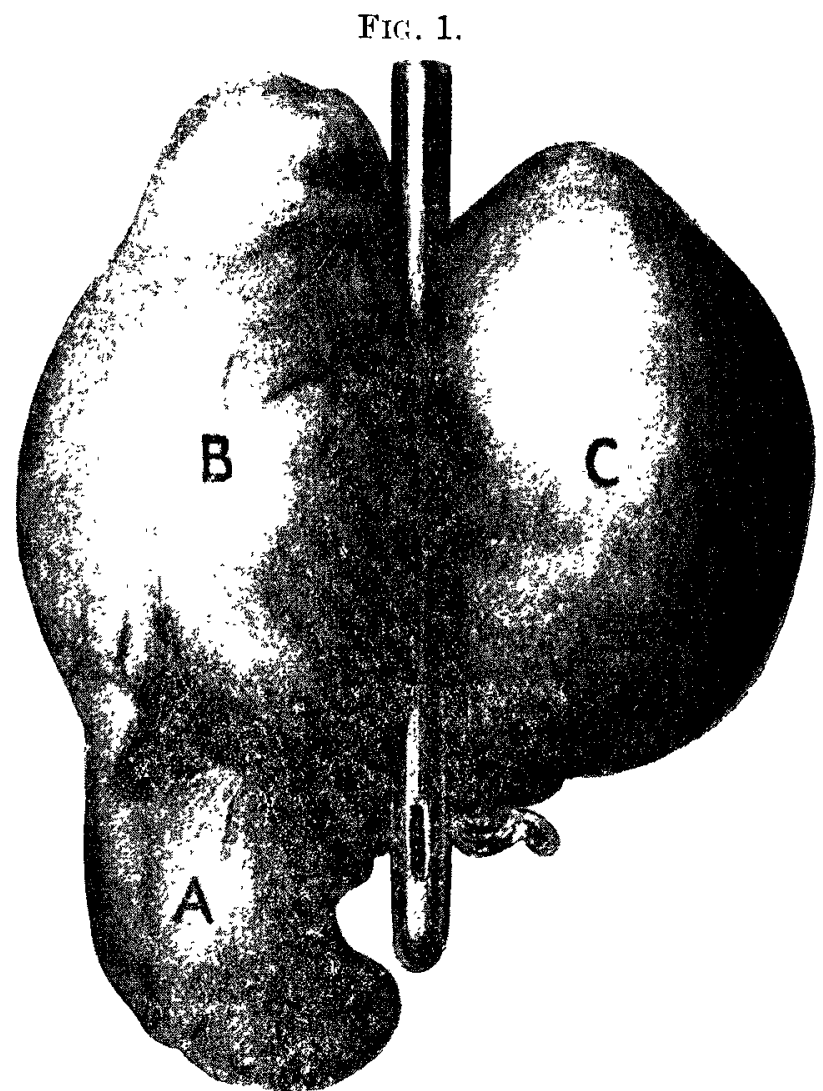

Prostate weighing 2 ounces removed from a patient aged 79 years (Case 15), actual size. C, Right lobe. B, Left lobe, continued into the bladter in the form of a so-called by the urethra

me that he passed and retained his urine better than at. any period of his life previously to operation.

The prostate (Fig. 1) wejghed two ounces, with each lobe enveloped in its true capsule. It is adenomatous but rather hard. It will be observed that the so-called " middle lobe" (A) is merely an outgrowth from the left lobe (B).

CASE 46.-The patient, aged 81 years, was seen in FIG. 2.

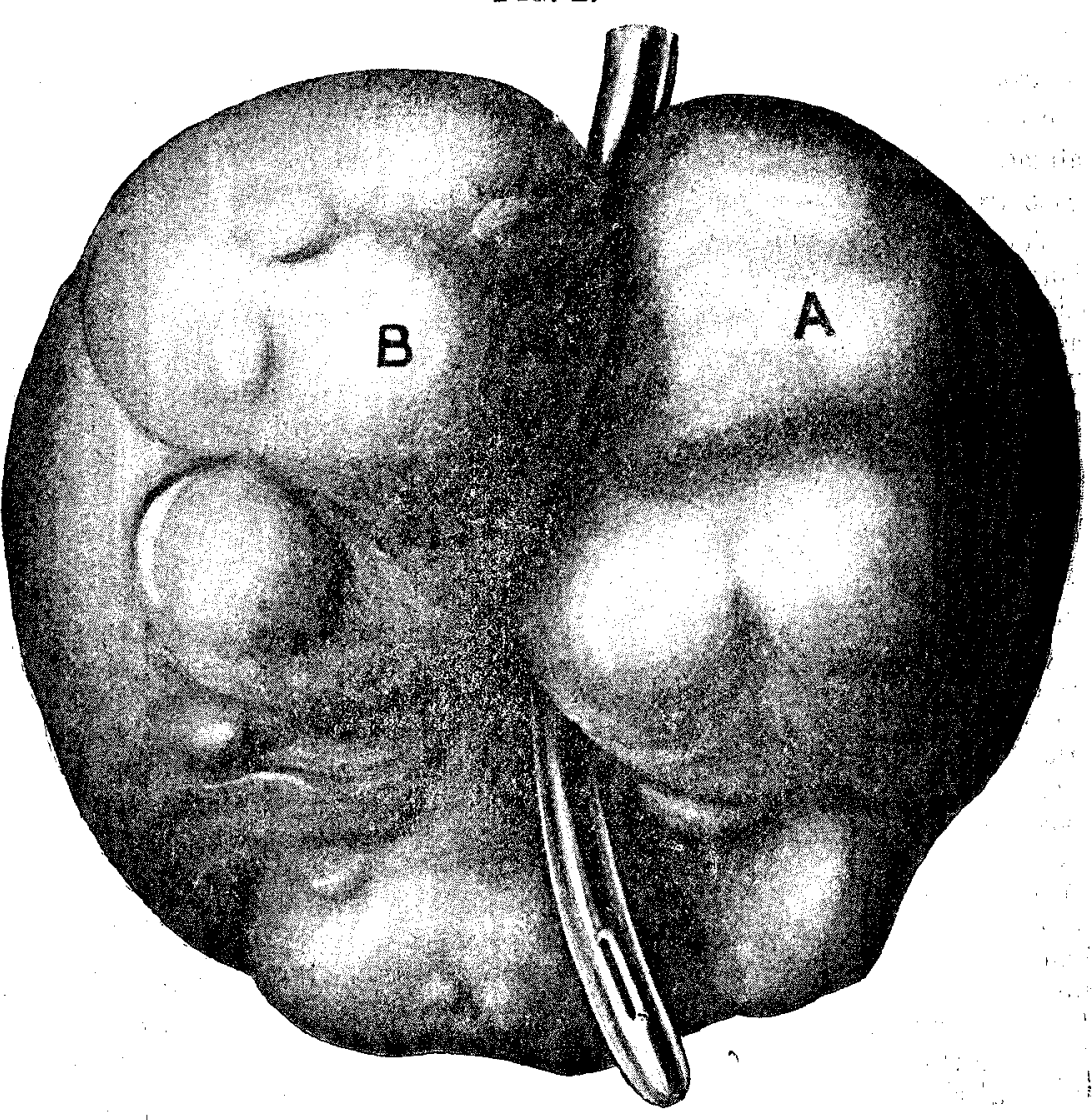

Prostate weighing $5+$ nunces remmed from a patient aged 81 years (Case 46). A, Right lobe. L', Left love 
consultation with Dr. H. J. Macevoy of . Bronclesbury on bleeding. His general health was bàl. Thién prostate wwas

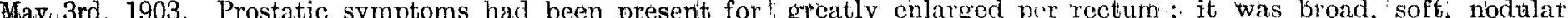
teniyears, gradually increasing in severity. 'There had been and moveable. On Nov. 19th, Mr. 'Shaw and "Colonel $C$ '? retention of urine for four years previously, relieved by Little, 1.M.S., being present, I removed the probtate gatheter, which has been employed ever since. There were, entire in its capsule with sevoral small calculi from the great frequency of micturition, intense pain at times, and hæmaturia. He had been seen from time to time by various London surgeons. Double vasectomy' was performed in 1900, but with no relief. His condition had been extremely miserable during the-last six months. I drew off eight ounces of residual urine containing much pus and blood; there was difficulty in -introducing the catheter. "The prostate was enormously, enlarged per rectum; it was soft, tense, and moveable. Cystoscopic examination on May 4th revealed an outgrowth of the left lobe of the prostate in the bladder of the size of a plum. The patient was in very feeble health and confined to bed. On May. 13th, Mr. J. W. Thomson Walker and Dr. Macevoy assisting, and Colonel W. G. H. Henderson, I.M.S., being present, I removed the prostate entire in its capsule. Some trouble was experienced in the enucleation owing to the stoutness of the patient, the finger with difficulty reaching the aspect of the gland towards the triangular ligament. The time occupied from commencing the suprapubic wound till the prostate was delivered from the bladder was 13 minutes. There was very little bleeding and no shock. The recovery was uneventful, the temperature remaining normal throughout. Some urine passed naturally on June 2nd and wholly in this way on the 5th. The patient went home on the 8th, 26 days after the operation, retaining and passing his urine naturally. He is now in excellent health, untroubled by any urinary symptoms.

The prostate (Fig. 2), which weighs five and a quarter ounces, is an excellent specimen of almost symmetrical adenomatous enlargement of that organ.

OASE 67.-The patient, aged 81 years, was seen with Mr. C. T. Knox Shaw on Oct. 29 th, 1903. Prostatic symptoms had been present for 30 years and gradually increasing. The catheter had been passed in June, 1901, showing 13 ounces of residual urine. Cystitis supervened in August. with much pus in the urine and rigors. The catheter was passed five or six times blacder. There was considerable bleeding and the patient daily in November, 1902. The sound was passed under an was feeble for some days after the operation. By the 29th anæsthetic in July, 1903, by another surgeon but no stone the suprapubic wound had closed so rapidly that it was was found. The patient had been entirely dependent on necessary to reinsert a small tube to prevent spasm of the the catheter since then, with much pain and occasional bladder. This was removed on Dec. 6th and on the same

FIF. 3.

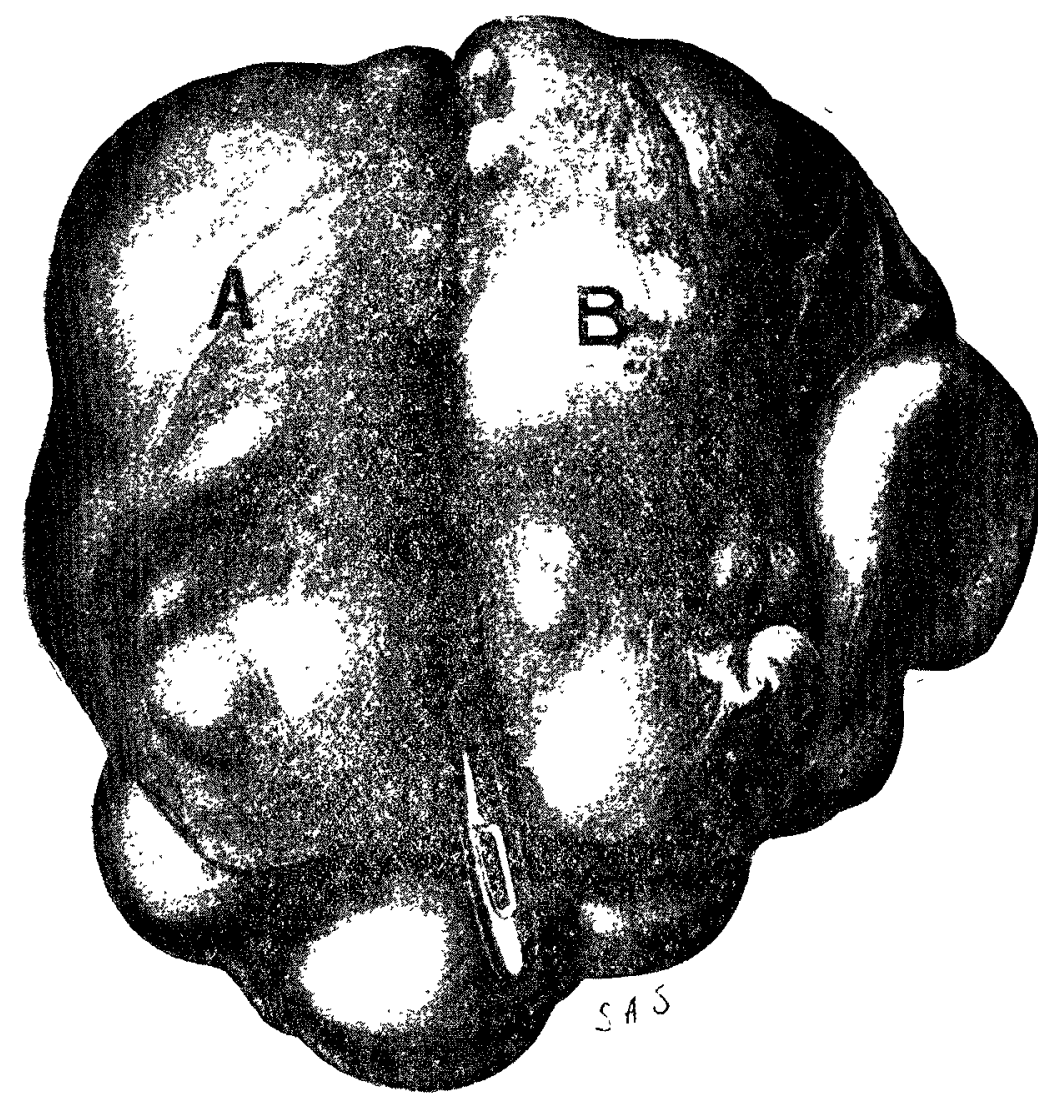

Prostate weighing $4 t$ ounces rmovel from a patient aged i 1 years day the patient began to pass urine naturally. The wound was closed on the 11th. On the 16 th he went out for a walk. I saw him two days ago. He is now, a year after operation, in excellent health and able to retain and to pass his urine naturally.

The prostate (Fig. 3) weighs four and a half ounces and is irregularly enlarged and bossy, the left lobe having been more prominent in the bladder than the right.

CASE 70.-.The patient, aged 84 years, was seen with Dr. H. E. Bruce Porter of Windsor on Nov.22nd, 1903. Prostatic symptoms liad been present for eight years. The catheter had been employed for six years and the patient had been entirely dependent thereon for five years; it was passed every two hours. The urine contained much blood and ropy muco-pus; it was alkaline and fotid. The catheter passed in $13 L$ inches before the urine flowed; a stone could be felt grating against its end. The prostate was enormously enlarged per rectum; it was roundly hilobed, smooth, soft, and moveable. The patient was emaciated, bearing the impress of terrible suffering. "Life not worth living under present condition," as he put it; morphine was given daily to mitigate the pain. He had an intermittent and irregular puise; the arteries stood out like whipcords all over his body. Rigors and fever occurred periodically. He came to London on Nov. 2rit 1 and his bladder was washed out twice daily. Un Dec. 4th, Mr. C. C. Braine being the anrethetist and Dr. Porter assisting, I opened the bladder suprapubically and found two phosphatic stones which were removed : they weighed two and a half drachms. Both ureters were dilated to such an extent that the index finger passed readily into them. The prostate was felt to be of the size and shape of 
a cricket-ball, and was jammed beneath the pubic arch, half of it lying in the bladder and half outside. It was enucleated entire in its capsule. Much force was required to separate it from the surrounding sheath. The time from commencing the suprapubic cystotomy till the prostate was delivered from the bladder was seven minutes. 'There was scarcely any bleeding or shock. The drainage-tube was removed on Dec. 7th. There was not an unfavourable symptom. No morphine had been given since the operation. "Talk of the pains of an operation," said the patient, "the last four days have been holidays from pain amongst many years." He sat up daily after Dec. 16th. He passed urine naturally by Dec. 20th. The wound was dry on the 23rd and the patient was walking about. On Jan. 2nd, 1904, he travelled home in good health and spirits, passing and retaining his urine naturally. $\mathrm{He}$ stated that he felt 20 years younger than his age-a truly grand old soldier who was present in the Afghan war in 1840. On July 26th last Dr. Porter wrote: "I saw old — to-day; he looks a marvel." In spite of the putrid state of the urine before operation the wound remained healthy and was free from phosphates throughout.

The prostate (Fig. 4), which weighs six and a quarter ounces, is a fine specimen of symmetrical enlargement with a small outgrowth in the form of a lip below the orifice of the urethra. This is the oldest patient on whom I have performed this operation and I submit that the result is a great surgical triumph considering his age, the large size of the prostate, the weak state of the patient, the presence of chronic cystitis with formation of phosphatic calculi, the dilated condition of the ureters from backward pressure, indicating a probability that the kidneys were much disease 1 and in spite of all this the complete restoration to health and function of the bladder.

CAsE 85.-The patient, aged 82 years, was seen with

$$
\text { FIG. } 5 \text {. }
$$

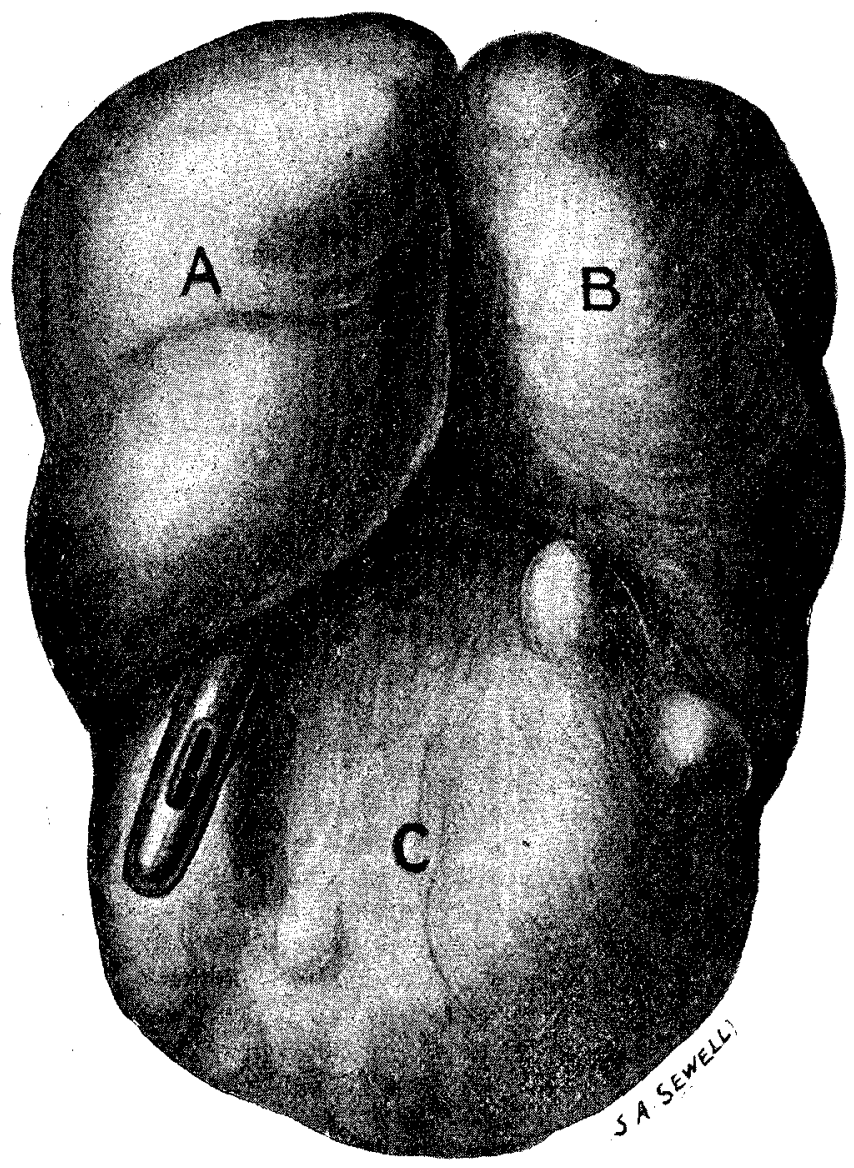

Prostate weighing $5 \frac{1}{4}$ ounces, removed from a patient ager 82 vears, A, Left lobe. B, Right lobe, presenting a tongue-
sbapei outgrowth, $C$, in the bladder.

Mr. J. L. Hewer of Highbury New Park on March 2nd, 1904. Prostatic symptoms had been present for 20 years and the patient had been entirely dependent on the catheter for ten years. He experienced great diffeulty and pain in introducing the catheter latterly, two hours being frequently spent in manipulating the instrument before it passed. He had had frequent attacks of cystitis, hæmorrhage, and orchitis and had undergone seven operations for vesical calculus. He had inguinal hernia requiring a truss. The prostate was much enlarged, soft, tense, and moveable; it could be felt bimanually. The urine contained pus and mucus. On March 7th I removed the prostate entire in its capsule, Mr. Hewer assisting. The time occupied was six minutes. The operation was well borne; recovery supervened without any unfavourable symptom, the temperature remaining normal throughout. Urine passed naturally on the 23 rd and the wound was dry on the 25th, 18 days after operation. The patient is now in excellent health, attending to his business daily. On July 19th he wrote to me: "The result of your operation has been entirely satisfactory. I am now able to pass and retain the urine as well as I ever did."

The prostate (Fig. 5), which weighs five and a quarter ounces, presented a large tongue-shaped outgrowth in the bladder growing from the right lobe. The rapidity with which the wound closed is remarkable in a patient aged 82 zears.

CASE 96.--The patient, aged 81 years, was seen with Mr. H. Huxley on Feb. 17th, 1904. Prostatic synuptoms had been present for five years. The patient was in great distress with an over-distended bladder. I passed a catheter and drew off 55 ounces of fairly clear urine. The prostate was much enlarged, rounded, smooth, and moveable. His general health was good. He passed some urine naturally for a few days but eventually he was completely dependent on the catheter. He was seen again with Mr. Huxley on May 3rd, when he travelled to London for operation, as catheter life was unbearable. His health was bad and he was very feeble. Rapid loss of flesh had taken place during the last two months. I enucleated the prostate on May 6th Mr. Huxley and Mr. Thomson Walker assisting. The gland was scarcely prominent in the bladder; it was firmly bound down by its sheath. There was hardly any bleeding. The prostate weighed two and a half ounces. Progress was most favourable till May 10th, when a severe attack of gout set in, followed by severe inflammation of the parotid glands which, however, did not suppurate. Though the wound kept clean throughout progress was slow, owing to the weak state of health. Urine was passed naturally by June 2nd and entirely per urethram by the 11th. The patient left the surgical home on the 16th and on the next day the suprapubic wound reopenea. A catheter was tied in till the wound closed again. The patient can now pass and retain his urine normally and his health generally is gradually improving.

CASE 121.-The patient, aged 83 years. was seen with Dr. R. M. H. Randell of Beckenham on August 10th, 1904. The usual prostatic symptoms had been present for 12 years. He had had cystitis eight years previously, since when he had employed a catheter, latterly three times nightly, and once or twice by day. He could pass small quantities of urine naturally by day but with great frequency of micturition, attended by pain. There was difficulty in introducing the catheter, attended by bleeding. The patient was in great distress and was suffering from chronic cystitis. The prostate was greatly enlarged per rectum and was bilobed, soft, moveable, and smooth ; it was easily felt bimanually. His general health was fair. On Sept. 15th, Dr. Randell assisting and Dr. F. de Havilland Hall and Mr. E. G. Renny of Colchester being present, I enucleated the prostate which weighed four ounces, in its capsule, leaving the urethra behind. The time occupied by the operation was five minutes. There were scarcely any bleeding and no shock. The patient made an uneventful recovery, urine passing naturally by Oct. 12th and the suprapubic wound being dry on the next day. He is now in good health and able to retain and to pass his urine as well as he ever did

CASE 123.- The patient, aged 83 years, consulted me on Oct. 22nd, 1903. He had had vesical calculi crushed in 1897 and again in 1900. During the last two years he had been in great distress from pain and frequency of micturition, being out of bed every half hour by night. The prostate was not enlarged per rectum but there was a nodule in the right lobe of stony hardness. The cystoscope revealed considerable enlargement of both lobes in the bladder and under the anæsthetic the nodule in the right lobe was felt bimanually to be of considerable size and gave rise to a suspicion of malignancy. The residual urine was only two and a half ounces. Employment of a catheter was advised. I saw the patient again in June, 1904, when he was no better. He would not persist in the use of the catheter, which, he sa d. made him worse. Early in September he begged for operation as he could not sleep owing to the pain and frequency of micturition. J'here was rapid loss of flesh during the last few months. On 
Sept.19th, Mr. C. C. Braine being the anæsthetist, I enucleated the prostate with some difficulty, the right lobe being very adherent to the surrounding tissues. There was scarcely any bleeding or shock. Section of the right lobe of the prostate (which weighed one and a quarter ounces) showed it to be carcinomatous. The patient made very favourable progress, passing urine naturally by Sept. 27th and the wound being practically closed by Sept. 30th, after which he sat up daily. On Oct. 15th whilst walking he felt faint, fell down, and rapidly expired from heart failure.

[Since this address was delivered on Oct. 20th, 1904, I have performed the operation in a further series of 34 cases, amongst whom there were two octogenarians. To complete the record to date I will give details of these two operations.]

CASE 155.-The patient, aged 83 years, was seen with Dr. J. C. Ferrier of South Norwood on Dec. 8th, 1904. Prostatic spmptoms had existed for five years; these had been much aggravated during the last two years. 'The patient had retention of urine 15 days previously and was entirely dependent on the catheter for ten days. There were much pain and difficulty in introducing the catheter and he was in great distress from cystitis, attempting to pass urine every few minutes. The prostate was enlarged, bilobed, tense, and moveable and was felt bimanually. 'The patient was stout; his general health was fair; the urine contained pus and albumin. On Dec. 10th he was conveyed to London by ambulance. After washing ont the bladder daily and preparing him for operation, on Dec. 20th, Dr. Ferrier assisting, opened the bladder suprapubically, removed a small urate stone weighing 39 grains, and then enucleated the prostate, weighing two and three quarter ounces, entire. The time occupied was five minutes. There was very little bleeding and no shock. No unfavourable symptoms supervened. Urine commenced to pass naturally on Jan. 9th and the wound was closed on the 12th. On the 16th the patient was walking about his room and on the 25th, when he left for home, he was in good health, passing and retaining his urine as well as he ever did. On Jan. 28th Dr. Ferrier wrote: "I am exceedingly pleased to see how well a man of his age has done after your operation."

CASE 160.-The patient, aged 80 years, was sent to me by Dr. A. M. Mitchell of Guildford on Jan. 11th, 1905. Prostatic symptoms had existed for four years. Retention of urine occurred one and three-quarter years ago and was relieved by catheter which had been regularly employed since then; he had been entirely dependent thereon for one year. He had had cystitis, hæmorrhages, intense pain in the penis during and after using the catheter, and the urine, which was alkaline, contained much pus and mucus. He had been in bed for seven weeks and was so feeble that he had to be conveyed to London by ambulance. The heart was very feeble with irregular and intermittent pulse. The prostate was bilaterally enlarged, soft, smooth, and moveable. Much pain and tenderness were felt during examination which were suspected to be due to the presence of vesical calculi. The patient's condition was very distressing, the catheter being introduced with much difficulty and pain. On Jan. 16th, Mr. C. C. Braine being the anæsthetist and Dr. Mitchell assisting, I removed four phosphatic calculi, weighing 185 grains, suprapubically and then enucleated the prostate entire without difficulty. The prostate projected into the bladder in the shape of an enormously hypertrophied cervix uteri with wide, irregular os. It weighed two and a half ounces. The time occupied was eight minutes, four of which were expended in removing the calculi. The operation was well borne and there was no shock. Progress has been most satisfactory, the patient soon regaining strength. Some urine was passed naturally on Jan. 24th and the wound was dry on Feb. 8th. He is sitting up daily in his room. He can pass and retain his urine (which is almost quite clear) as well as ever and will leave for the country in a few days.

Harley-street, $\mathrm{w}$

Scottish Poor-Law Medical Officers' AssoCIATION.-At a meeting of the executive council of this society held on Feb. 15th at Glasgow, Dr. William Cullen, vice-president, presented Mr. W. L. Muir with several handsome pieces of silver plate in appreciation of his indefatigable services as secretary of the association. The presentation was made by the unanimous wish of the association.

\section{ENELECTROLYSIS : AN IMPROVED METHOD OF OPERATING ON SUPERFLUOUS HAIRS.}

BY BALMANNO SQUIRE, M.B. LOND., SURGEON TO THE BRITISF HOSPITAL FOR DISEASES OF THE SKIK.

ThE extreme dislike evinced by most women to engaging in the habit of shaving when they are the subjects of superfluous hair, although this method is probably the best they can adopt for ridding, themselves of the disfigurement, and their almost invariable insistence on having the hair removed by electrolysis, renders any improvement in operating with the electrolytic needle a desideratum. The operation as hitherto practised is by no means ideal as to the results obtainable from it even in the hands of expert operators, and instances are by no means rare in which the effects of the operation have produced considerably more disfigurement than the original condition; the procedure has consequently in great measure fallen into discredit. As hitherto practised. the hair is taken as the guide for the direction in which the needle should be pushed with a view to its point reaching the root or papilla from which the hair grows and after the needle has been allowed to remain in situ for a period presumably long enough for the current to destroy the papilla, the hair thus operated on is seized by a pair of tweezers and very gentle traction is made on it; then if the hair comes out as if quite loose the hair papilla is considered, and with good reason, to be destroyed.

Quite recently, however, another mode of setting to work occurred to my mind-namely, to pull out the hair first and then to pass the needle into the hole left by the extraction of the hair. This difference, trivial as it seems, alters the whole character of the operation. It renders the destruction of skin that necessarily accompanies the destruction of the papilla very much less, and in consequence the scarring left after the operation is not very noticeable. It makes the operation a much more certain one-indeed, it converts it into an operation of precision. The upper lip, bitherto always by far the most difficult region to operate on, becomes as easy to deal with as the chin. One very important advantage of it is that it makes the procedure much more expeditious and another is that the pain caused by the introduction of the needle is notably less. My doubts as to this improvement before I had tried it were that in pulling out the hair first, often in itself a difficult thing to see, one at once loses one's only guide not only as to the point at which the needle should be inserted but also as to the direction in which it should be pushed; that, even if one could contrive to see the orifice of the hair follicle, one has lost in the plucked-out hair the clue to the precise direction of its slant. Then I feared that in passing the needle down the hair follicle the point would get caught in the wall of the follicle and thus diverted from the proper direction, and, lastly, I foresaw that the only test of success-namely, the hair yielding easily on traction with the tweezers-was rendered impossible. On trial, however, I found that not one of these objections was valid.

The drawbacks to the method hitherto in use are, on the contrary, by no means imaginary. The direction of the hair outside the skin is not a trustworthy indication of its direction in the substance of the skin. It shows the direction of the slant but not the degree of the slant, inasmuch as the majority of the bairs directly they $i$-sue from the skin become at once curved. I am aware that it has been claimed that a catheterisation by the needle of the hair-filled follicle is possible and that thus the hair-filled follicle will guide the sharply pointed needle to its right destination. A pretty considerable experience of the operation has convinced me that this is not so or at the most happens only in an extremely small percentage of the hairs operated on. As a rule the point of the needle, even when very carefully and slowly introduced, pierces the skin by the side of the follicle and arrives at its destination at a spot on one side of, and at a variable distance from, the papilla. The consequence is that an unnecessary destruction of the skin has to be produced in order that the destruction may radiate until it has reached the papilla; in short, that this has to take rlace visibly before the hair will come out under really gentle traction with the tweezers. Then, on pushing the reedlepoint into the skin, however slowly, so that its electrolytic 